\title{
As memórias dissonantes do carvão: atividades educativas do Centro de Memória e Documentação da UNESC - CEDOC
}

The Dissonant Memories of Coal: Educational Activities of the Centro de Memória e Documentação, UNESC - CEDOC

Michele Gonçalves Cardoso* Tiago da Silva Coelho**

\section{RESUMO}

O presente trabalho objetiva discorrer sobre as atividades educativas desenvolvidas no Centro de Memória e Documentação da Universidade do Extremo Sul Catarinense - CEDOC. A instituição promove diversas ações em parceria com as escolas de educação básica com a intenção de possibilitar reflexões sobre a cidade de Criciúma e região por meio de seus acervos. Nosso enfoque neste artigo são as oficinas organizadas e realizadas durante o ano de 2016 e que trataram sobre diversos aspectos das atividades carboníferas realizadas na cidade. As memórias e a materialidade a respeito dessas atividades são bastante positivadas, silenciando, por vezes, narrativas e espaços que apresentam narrativas dissonantes, marginais e/ou sensíveis, de modo que as oficinas realizadas pelo CEDOC propuseram repensar as percepções e discursos oficiais sobre a cidade e a região carbonífera. As oficinas realizadas em 2016 foram reconfigura-

\section{ABSTRACT}

This paper aims to discuss the educational activities developed at the Centro de Memória e Documentação da Universidade do Extremo Sul Catarinense - CEDOC. The institution promotes various activities in partnership with schools of basic education with the intention of allowing reflections on the city of Criciúma and region through its collections. Our focus in this article is the workshops organized and held during the year of 2016 and which dealt with various aspects of the coal activities carried out in the city. The memories and materiality regarding these activities are quite positive, sometimes silencing narratives and spaces that present dissonant, marginal and/or sensitive narratives, so that the workshops held by CEDOC proposed to rethink the official perceptions and speeches about the city and the coal region. The workshops held in 2016 were reconfigured and gave rise to several

* Universidade do Extremo Sul Catarinense (UNESC), Criciúma, SC, Brasil. michelegc@unesc.net ** Universidade do Extremo Sul Catarinense (UNESC), Criciúma, SC, Brasil. tiagocoelho@unesc.net 
das e deram origem a vários outros projetos que continuam em andamento na instituição.

Palavras-chave: memórias dissonantes; atividades educativas; exploração carbonífera. other projects that are still ongoing at the institution.

Keywords: dissonant memories; educational activities; carboniferous exploration.

A cidade de Criciúma, localizada no sul de Santa Catarina, possui profundas marcas que demonstram sua relação com as atividades carboníferas. A extração do carvão mineral na região sul do estado foi um elemento fundamental para o desenvolvimento econômico, social e cultural das cidades, direta ou indiretamente, envolvidas nesses processos. Criciúma tornou-se polo da região concentrando em seu território uma parte significativa das estruturas relacionadas às atividades carboníferas, as quais tiveram início na década de 1910 prolongando-se de maneira por vezes instável até a década de 1990. Atualmente, a extração e o transporte do minério ainda ocorrem, porém, o setor não é mais considerado um determinante econômico, especialmente para Criciúma, que não apresenta mais atividades de exploração do mineral em seu território.

Entretanto, apesar de seu enfraquecimento econômico, a cidade possui fortes vínculos com as memórias em torno das atividades carboníferas. $\mathrm{Na}$ década de 1940, Criciúma recebeu o título de Capital Nacional do Carvão, nomeação que de muitas formas ainda é ostentada e valorizada no município. Mesmo sendo uma identidade em disputa com o título de Cidade das Etnias, ${ }^{1}$ a identidade carbonífera é constantemente reativada por meio de memoriais, exposições artísticas e de cunho histórico, exibição de documentários e pelo próprio clube de futebol, o Criciúma Esporte Clube, que propositadamente ostenta as cores amarelo, preto e branco, que representam o ouro negro, ou seja, o carvão mineral.

Para além de ações pontuais que reativam a memória das atividades carboníferas, as marcas do carvão estão presentes no desenho urbano, nos nomes dos bairros, nos monumentos erguidos, nas estruturas da Estrada de Ferro Dona Teresa Cristina, nas edificações das empresas carboníferas, nas "bocas" de minas ainda abertas, na gravidade da poluição de rios e solo, na quantidade de rejeito de carvão (pirita) espalhada na cidade, na mina de visitação Otávio Fontana e, principalmente, nas memórias dos trabalhadores e trabalhadoras envolvidos/as nas diversas atividades vinculadas ao carvão. 
Nesse sentido, observando brevemente o cenário apresentado, podemos nos interrogar sobre como esse processo tão marcante para a cidade e para a região é abordado em sala de aula, especialmente, nas aulas de História. Será que essa especificidade regional encontra espaço entre os conteúdos curriculares demarcados pelos documentos regulatórios e pelo livro didático? E caso a temática seja abordada, quais são os elementos apresentados? Qual o papel das instituições não formais de educação nesse processo? Pretendemos nesse artigo contribuir com algumas reflexões provocadas por essas interrogações e também, pelas ações educativas desenvolvidas no Centro de Memória e Documentação da UNESC - CEDOC, que atuando há 20 anos na região, procura desenvolver um diálogo estreito com as escolas de educação básica objetivando divulgar seu acervo e contribuir para a elaboração de novas abordagens sobre as atividades carboníferas do sul de Santa Catarina.

\section{OS DIFERENTES COMPASSOS AUDÍVEIS SOBRE AS ATIVIDADES CARBONÍFERAS}

Podemos observar que na cidade de Criciúma ocorrem constantemente processos de reativação do discurso de cidade carbonífera. Entretanto, essas ações demonstram certa ambiguidade em torno desta concepção identitária. O discurso de cidade carbonífera está marcadamente centrado numa perspectiva de modernização e progresso, buscando uma narrativa linear em que atrela a descoberta do mineral aos imigrantes e, que, desde este fato, a cidade teria se desenvolvido a partir do trabalho incansável de todos os agentes envolvidos, que, no caso desta perspectiva, seriam mineradores e mineiros. Este discurso oblitera importantes questões presentes no cotidiano de uma cidade carbonífera, enfatizando apenas uma narrativa homogênea e harmoniosa, que sustenta inclusive, o status de município referência para a região sul catarinense.

Contudo, esta narrativa invisibiliza os diversos elementos que nos proporcionam conhecer as atividades por outros aspectos. Podemos destacar, por exemplo, as edificações para beneficiamento e transporte do carvão, que hoje compõem o cenário da cidade. A maioria está desativada e abandonada, ruindo pela ação do tempo. Situadas em bairros periféricos ou mesmo na principal avenida da cidade, essas estruturas são consideradas esteticamente pouco aprazíveis para o olhar dos citadinos e de turistas e, por isso, não são alvos de pro- 
cessos de revitalização, tampouco são percebidas como potencial para a patrimonialização ou, especialmente, como representativas do patrimônio industrial.

Sobre as ações de preservação do patrimônio na cidade destacamos que até o ano 2000, somente dois bens eram preservados pelo poder público municipal de Criciúma: o prédio da antiga sede da prefeitura municipal, atual Casa da Cultura Neusa Nunes Vieira, e a mata atlântica preservada no bairro Mina União. Nos anos que se seguiram foram realizados outros 19 processos de tombamento em nível municipal, totalizando 20 edificações e monumentos salvaguardados, com a adição da mata nativa já citada. Observa-se na totalidade dos bens edificados a valorização de quatro tipologias principais que se confundem na percepção da sociedade. São edificações e monumentos em sua maioria alusivos às memórias da imigração (4), religiosa (6), da modernização/ urbanização (3) e do carvão (6). No entanto, podemos entender que quase todas as edificações apontadas na tipologia religiosa também fazem alusão aos processos de imigração ocorridos na cidade ao final do século XIX (MONTEIRO, 2013).

Se focarmos nos seis bens tombados alusivos à memória do carvão, encontramos: a ponte de ferro do Bairro São Roque, ${ }^{2}$ a Mina Modelo Caetano Sônego, ${ }^{3}$ o antigo prédio do Departamento Nacional de Produção Mineral, hoje Centro Cultural Jorge Zanatta; a caixa de embarque de carvão do bairro Laranjinha, o Monumento aos Homens do Carvão, ${ }^{4}$ e a chaminé do bairro Próspera, parte da antiga usina termoelétrica que gerava energia para a cidade antes da rede elétrica estadual.

Nessa rápida lista não se encontra a Casa do Agente Ferroviário, talvez a mais importante edificação para a discussão sobre o patrimônio cultural na cidade de Criciúma, pois a derrubada dessa edificação e sua reconstrução foram o estopim para a reestruturação do setor na cidade e possibilitou a nova leva de tombamentos posteriores ao ano 2000. Nota-se a escolha por bens e monumentos que ressoem a existência da atividade carbonífera na cidade, porém nenhum dos bens edificados manteve-se com qualquer uso que se aproxime do original. Em alguns casos, o passado dessas edificações não é evidenciado, sendo pouco rememorado pela população que transita ou faz uso desses locais, quando não estão abandonadas como a Mina Modelo Caetano Sônego fechada por alegados motivos de segurança; descaracterizadas como o caso da caixa de embarque do bairro Laranjinha; e/ou destruídas como a ponte de 
ferro do bairro São Roque, atingida por enxurrada resultante de uma enchente em $2010 .^{5}$

É possível observar que os bens patrimonializados alusivos à memória da exploração carbonífera em Criciúma ressaltam um passado pouco conflitivo, demonstrando um discurso oficial que reflete uma memória homogênea e harmônica sobre este processo histórico tão complexo para uma região que ainda hoje assiste aos seus desdobramentos com reflexos positivos e negativos para a vida urbana e de seus habitantes. Em 2017, o projeto de pesquisa Memórias e Identidades: as estruturas carboníferas como Patrimônio Cultural de Santa Catarina mapeou somente em Criciúma a existência de mais de 35 conjuntos de bens e lugares alusivos à exploração da indústria carbonífera e os processos decorridos ao seu redor (COSTA e OSÓRIO, 2017). Contrastando com os 6 bens tombados, pouco ou nada preservados pelo poder público municipal, é possível observar uma vontade política para o silenciamento da mineração na cidade, silêncio esse que é rompido reiteradas vezes pelas memórias individuais e coletivas e pelas estruturas ainda presentes na cidade, como já mencionado.

Para além das edificações e de sua materialidade, as memórias dos tensionamentos entre a classe trabalhadora e patronal pouco aparecem nas narrativas da cidade carbonífera. A intensa atuação do sindicato dos mineiros deu à cidade um outro título um pouco menos conhecido de seus munícipes: cidade mais comunista do Brasil. As constantes greves por melhorias nas condições de trabalho e, também, salarial transformavam a cidade em palco de guerra, com direito ao uso de dinamites nas difíceis negociações com as carboníferas. Relacionadas ainda ao trabalho nos subterrâneos das minas, as reivindicações por equipamentos de segurança estavam pautadas nos corriqueiros acidentes de trabalho que incapacitavam temporária ou permanentemente os trabalhadores. Nos episódios mais graves, os acidentes causavam a morte do trabalhador, sendo um dos acontecimentos mais impactantes o desastre ocorrido na Mina de Santana, ${ }^{6}$ no município de Urussanga em que 31 mineiros perderam a vida.

A morte também chegava a médio prazo quando era decorrente das inúmeras doenças relacionadas à mineração, especialmente a pneumoconiose. A doença pulmonar é resultado da inalação da poeira do carvão que se espalha pelo pulmão e pode levar à obstrução das vias aéreas. Um incontável número de trabalhadores perdeu a vida em decorrência da doença, o que apontava a 
emergência da adequação para o trabalho nas minas de carvão. Importante ressaltar que quando o trabalhador estava incapacitado de desenvolver a função, ou mesmo quando falecia no trabalho, as famílias que ocupavam as casas das vilas operárias eram, em muitos casos, despejadas o que aumentava ainda mais a dor e a revolta.

Desse modo, ao mencionarmos que a cidade possui uma relação de ambiguidade com sua memória carbonífera, intentamos observar como essa identidade - sua materialidade e imaterialidade - são evocadas ou esquecidas em certos momentos, ou ainda, como são selecionadas em seu aparecimento público. Evidentemente que todo processo de escolha implica em esquecimentos, mas é notório que as narrativas da cidade carbonífera contemplam quase que exclusivamente narrativas positivadas e conciliatórias, o que não impede que outras vozes ecoem em contraste com essas visões. Nesse sentido, poderíamos afirmar que os bens que remetem às atividades carboníferas, bens tombados ou com possibilidade para tombamento, possam ser considerados um patrimônio dissonante? Um patrimônio difícil?

Pensando no termo "dissonante", as autoras Cristina Meneguello e Viviane Borges (2018, p. 362) destacam que a elaboração da fórmula musical de "patrimônio dissonante" elaborada por John Tunbridge e John Ashworth buscava cunhar um termo que pudesse descrever os locais em que há percepções díspares sobre um evento ocorrido, como por exemplo, percepções de algozes e de vítimas. Em geral, esses bens provocam debates éticos e oscilam entre ações de preservação e de esquecimento, já que evocam memórias de grupos sociais considerados incômodos, marginais e historicamente apartados da memória pública.

Essas vozes dissonantes passaram a ser atentamente ouvidas a partir das demandas contemporâneas que atuaram no processo de ressemantização do conceito de patrimônio, e também na própria reconfiguração do campo. Diversas ações foram protagonizadas por diferentes atores sociais que produziram resistências a respeito dos atos de lembrar e de esquecer. Esse movimento proporcionou novas abordagens, a visibilização de narrativas silenciadas, a difusão de saberes, a materialização de conhecimentos e a reivindicação identitária e por direitos. Nesse exercício, o patrimônio cultural passou por um processo de rearticulação que produziu novos sentidos e enfoques, como por exemplo, o patrimônio prisional, industrial, funerário, LGBT, entre outros. 
Nesse contexto, a ampliação dos debates em torno dos espaços que por muito tempo foram relegados como os locais que remetem ao sofrimento, à punição, à exceção e à morte, geraram a necessidade de pensar esses patrimônios a partir de um complexo exercício de conceituação, dando o contorno de "patrimônios difíceis ou sombrios". Esses patrimônios "podem reunir a função de memorial ou de local de peregrinação com a finalidade de rememoração coletiva e de reconhecimento de direitos e de reparação" (MENEGUELLO, 2020, p. 245). Também intencionam evitar a ocultação de fatos e o descrédito das vítimas, proporcionando por meio da memória da dor a perplexidade e a possível empatia, contribuindo ainda para a elaboração de políticas de reparação e justiça, ou mesmo, auxiliando as vítimas e seus descendentes a lidar com o passado (MENEGUELLO, 2020, p. 246).

Essa perspectiva também redimensiona o próprio conceito de patrimônio como atrelado à preservação do belo e do bom, o que amplia as interações, os objetivos e os protagonistas desses processos. Desse modo, dialogando com as definições em torno da ideia de patrimônios dissonantes e difíceis, conseguimos observar em ambas as contribuições maneiras de mobilizarmos os patrimônios que remetem aos espaços e às memórias das atividades carboníferas em Criciúma.

As vozes dissonantes em torno desses patrimônios denotam, como já explanado, a predominância das narrativas que positivam as memórias do carvão, pautadas nos discursos de progresso e modernização, e difundidas por aqueles intitulados por José Paulo Teixeira (1996) como os donos da cidade. Outras vozes que ecoam dão conta de narrar as experiências pouco materializadas que registram o sofrimento, a dor e a morte nos espaços de trabalho dos mineiros; a vivência em meio à intensa poluição ambiental; a elevadíssima taxa de mortalidade infantil; e as estratégias de controle vivenciadas nas vilas operárias. Essa dicotomia nas narrativas não deve ser resumida apenas numa relação de luta de classes, ou de narrativas contrapostas, mas sim, como possibilidade de contemplar a multiplicidade de narrativas, memórias e identidades.

A multiplicidade de memórias a respeito desses processos não está ausente na cidade. Além de sua perpetuação por meio das lembranças e da oralidade, dezenas de trabalhos acadêmicos se dedicaram a registrar essas narrativas garantindo que as vozes dissonantes continuassem reverberando, muitos deles realizados dentro do Grupo de Pesquisa Memória e Cultura do Carvão. Men- 
cionando apenas alguns desses trabalhos, podemos destacar as produções de Marli de Oliveira Costa (1999; 2009), Giani Rabelo (2008) e Ismael Gonçalves Alves $(2009 ; 2014)$, como contribuições para pensarmos o cotidiano e as práticas de saúde e assistência nas vilas operárias; as relações de trabalho e a atuação do sindicato dos mineiros podem ser aprofundadas a partir da leitura de Terezinha Gascho Volpato (1984; 2001) e Antonio Luiz Miranda (2013); o trabalho das mulheres na atividade de "escolhedeiras" de carvão pode ser conhecido no trabalho de Carlos Renato Carola (2002). E, ainda, as problemáticas em torno da poluição ambiental na região são temas dos trabalhos de Carlos Renato Carola com Carlyle Torres Bezerra de Menezes (2010) e com Nilson Dassi (2014), o transporte e as relações econômicas que envolveram a exploração carbonífera pelos trabalhos de Alcides Goularti Filho (2002; 2004).

Entretanto, as produções acadêmicas e a materialidade das atividades carboníferas na cidade parecem apontar para lados antagônicos. Assim, retomamos a pergunta que motivou o texto: e na escola? Como essas memórias e esses bens são mobilizados nas aulas? E em que medida um espaço não formal de educação pode contribuir para pensarmos a temática a partir da multiplicidade de seus agentes? Ao mobilizarmos o termo espaço não formal tomamos por base a conceituação proposta por Maria da Glória Gohn, que designa como

um processo com várias dimensões tais como: a aprendizagem política dos direitos dos indivíduos enquanto cidadãos; a capacitação dos indivíduos para o trabalho, por meio da aprendizagem de habilidades e/ou desenvolvimento de potencialidades; a aprendizagem e exercício de práticas que capacitam os indivíduos a se organizarem com objetivos comunitários, voltadas para a solução de problemas coletivos cotidianos; a aprendizagem de conteúdos que possibilitem aos indivíduos fazerem uma leitura do mundo do ponto de vista de compreensão do que se passa ao seu redor; a educação desenvolvida na mídia e pela mídia, em especial a eletrônica etc. (GOHN, 2009, p. 31)

Em contraposição aos espaços de escolarização formal, a aprendizagem estimulada nos espaços não formais é pautada na flexibilidade, sendo menos hierárquica e burocrática, possibilitando ações dialógicas e versáteis. Mas, assim como no espaço formal de educação, as atividades desenvolvidas nos espaços não formais exigem planejamento, organização, objetivos e metodologias, 
que em alguns casos, como na atividade relatada neste artigo, podem conciliar os propósitos de ambos os espaços.

\section{OUTRAS VOZES}

Buscando contribuir para a ampliação de narrativas sobre a exploração carbonífera na região de Criciúma, o Centro de Memória e Documentação da UNESC - CEDOC propôs, a partir de seus acervos, dar atenção às memórias dissonantes envoltas nesses processos. O CEDOC é um setor vinculado ao curso de História da Universidade do Extremo Sul Catarinense - UNESC, criado no ano 2000, com a função inicial de salvaguardar processos judiciais da Comarca de Criciúma que, a princípio, seriam incinerados, já que havia esgotado o prazo legal de permanência em poder do fórum. A partir dessa iniciativa de preservação, a instituição passou a adquirir novos acervos que tratam da memória da região sul de Santa Catarina, desde documentos sobre os processos de colonização até as discussões dos mundos do trabalho.

Entre os acervos que compreendem as memórias das atividades carboníferas estão os documentos reunidos pelo Grupo de Pesquisa Memória e Cultura do Carvão, que era composto por professores/as e alunos/as de diferentes áreas, marcando sua atuação interdisciplinar. O grupo atuou no início dos anos 2000 registrando as histórias e memórias dos moradores da região, especialmente no que diz respeito à presença da atividade carbonífera no sul de Santa Catarina. O CEDOC ainda conta com acervos sobre processos trabalhistas da comarca de Criciúma, como também processos relativos aos acidentes de trabalho nas minas de carvão. É interessante ressaltar que a tônica que se promoveu em torno do Grupo Memória e Cultura do Carvão foi a de ressaltar traços das atividades carboníferas que se referiram ao cotidiano, poluição ambiental, assistência social, história econômica da região, potencializando uma memória crítica com o passado desta atividade.

Entendendo as vicissitudes da memória relativa à exploração carbonífera do sul de Santa Catarina, que oscilam entre a valorização de seus benefícios e a condenação da atividade como nociva para toda a região, o CEDOC, por meio de seus três laboratórios - Documentação, Conservação e Restauro; História Oral, Imagem e Som; e Educação para o Patrimônio - promoveu a oficina Indústria Carbonífera em Criciúma: trabalho, cidade e operários/as objeti- 
vando prover o diálogo entre o espaço da universidade e as escolas da rede pública municipal de educação de Criciúma.

A organização e o projeto da oficina foram realizados em colaboração com os professores e professoras de História da Secretaria Municipal de Educação de Criciúma, que, durante o ano de 2016, foram parceiros na elaboração do projeto, na implementação e no desenvolvimento dessas atividades. Tendo por base as experiências compartilhadas pelos professores e professoras, algumas inquietações foram surgindo no processo, principalmente aquelas relativas ao trabalho com os temas sensíveis da mineração. A oficina buscava discutir os temas considerados delicados utilizando as fotografias e documentos existentes nos acervos do CEDOC, relacionando problemáticas locais com conteúdos tradicionais do currículo escolar da disciplina de História, de modo a ressaltar a importância de se discutir as relações sociais da cidade nas épocas de exploração carbonífera em comparação a processos clássicos como a Revolução Industrial, as condições de trabalho e as lutas trabalhistas.

A oficina desenvolvida consistia em uma atividade de educação patrimonial, cujo enfoque eram os documentos, principalmente fotografias, disponíveis nos fundos Memória e Cultura do Carvão, Justiça do Trabalho e Acidentes de trabalho. A proposta foi articulada para complementar as atividades desenvolvidas em sala de aula, entendendo que, nessa situação, a oficina realizada no CEDOC seria uma extensão das atividades de educação formal promovidas na escola.

A ação educativa proposta nas oficinas do CEDOC não pensa a educação patrimonial como uma metodologia própria, encerrada em si mesma, mas sim, como uma proposta que alia o campo da educação e do patrimônio, sem deixar de observar os objetivos já reconhecidos da educação patrimonial, que seriam “promover a sensibilização sobre a importância do patrimônio, e de sua preservação, na formação de sujeitos de sua própria história, que atuem na reivindicação de seus direitos coletivos e no fortalecimento de sua cidadania" (BEZERRA, 2020, p. 63). É importante deixar claro que o enfoque foi dado à discussão de memórias dissonantes sobre o carvão na cidade de Criciúma, porém a oficina fora construída para pensar o tratamento ético e sensível com as memórias difíceis e com a educação formal desenvolvida nas aulas de História das escolas participantes.

Segundo Maria Stephanou, as propostas de ação educativa possibilitam 
a compreensão de uma outra linguagem, inscrita nos indícios de um passado, que se constitui como um dos elementos de nossa ancestralidade; a compreensão das representações de diferentes épocas, expressas na produção de determinados acervos; a elaboração de uma crítica dessa linguagem, dos discursos que os museus/acervos manifestam, sejam eles nacionalistas, ou aristocrático, ou machista, ou popular, ou imperialista, ou etnocentrista, ou comunitário, [...] o incentivo não a um culto às ruínas, mas, nas palavras de Besset, "uma sensibilização nostálgica da memória”; a leitura, não menos importante, de diferentes temporalidades que, segundo Chartier [...] possibilitam que "o presente seja o que é, herança e ruptura, invenção e inércia a cada vez, e esta segue sendo uma tarefa dos historiadores e sua responsabilidade principal para com seus contemporâneos". (STEPHANOU, 2014, p. 19-20)

Nessa perspectiva, a ação educativa pretendia possibilitar aos alunos/as reflexões sobre a atividade carbonífera em Criciúma, destacando as estruturas do carvão - e seus espaços de memória -, como também as relações de trabalho, o movimento operário mineiro, o trabalho infantil, a presença das mulheres nessas atividades e, ainda, as transformações urbanas e ambientais promovidas pela extração do carvão. Por sugestão dos professores e professoras da educação básica, a ação foi direcionada às turmas dos $8^{\circ}$ e $9^{\circ}$ anos, período em que os/as alunos/as estudam conteúdos relacionados a conceitos como industrialização, modernização e urbanização.

Os objetivos elencados pela equipe do CEDOC e pelos profissionais da educação básica estavam bastante claros e organizados. Entretanto, o maior desafio para a realização da oficina foi a escolha dos documentos. O acervo fotográfico, por exemplo, possui diversas imagens de trabalhadores e trabalhadoras nas minas de carvão que são pouco conhecidas do grande público ou, mesmo quando já divulgadas em outros suportes, não apresentam problematizações a respeito de alguns elementos.

A metodologia escolhida, visava privilegiar uma aproximação entre os/as alunos/as e um passado recente da cidade e que ainda permanece marcado nas construções e memórias compartilhadas pelos habitantes da região. Assim, o uso de fotografias possibilita uma dupla abordagem: ela pode ser considerada como referência à história, mas também como legado ao futuro. 
É importante considerar a fotografia simultaneamente como imagem/documento e como imagem/monumento (LE GOFF, 1985). No primeiro caso, considera-se a fotografia a marca de uma materialidade passada, que nos informa sobre determinados aspectos desse passado, como condições de vida, moda, infraestrutura urbana ou rural, condições de trabalho etc. No segundo caso, a fotografia é um símbolo, aquilo que, no passado, a sociedade estabeleceu como a única imagem a ser perenizada para o futuro. Como documento e monumento, a fotografia informa e também conforma visões de mundo. (MAUAD e LOPES, 2012, p. 264)

Poderíamos exemplificar essa situação a partir da análise das fotografias que demonstram a presença do trabalho feminino nas atividades de escolha do carvão. As fotografias das chamadas "escolhedeiras" foram temas de diversas exposições, como também, publicadas em alguns livros sobre essa atividade. Entretanto, a circulação das fotografias e seu recorte temático, ainda promove a invisibilidade de outros agentes presentes nas imagens: as crianças. A presença das crianças no ambiente de trabalho ainda é pouco problematizada tornando-se necessário reflexões sobre a atuação de mão de obra infantil nesses espaços. O "auxílio" na atividade de escolha ou mesmo no transporte do carvão nos permite questionar como eram estabelecidas as relações de trabalho, como a própria remuneração, e, de modo geral, pensar as características da infância nesse período.

Figura 01 - O trabalho infantil junto a escolha de carvão (s. d.)
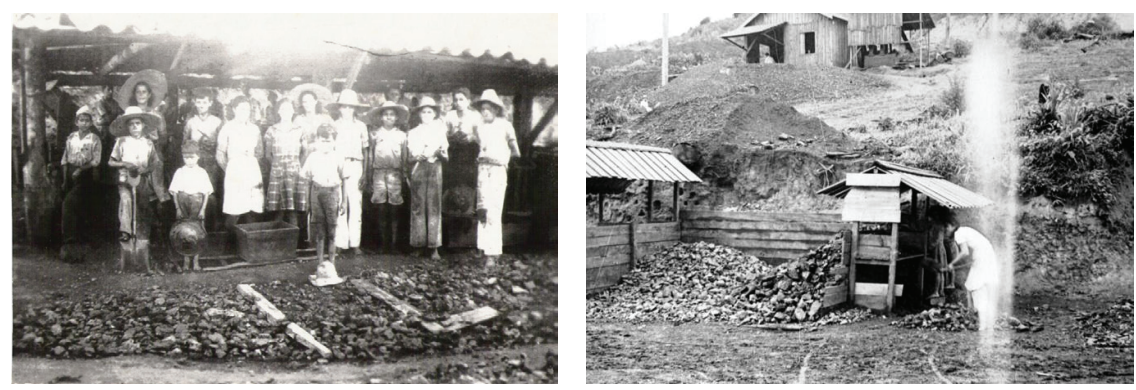

Fonte: Acervo CEDOC/UNESC

Outras fotografias registram o cotidiano de trabalho no subsolo das minas evidenciando o ambiente insalubre e a ausência de equipamentos de segurança apropriados. A maioria dos trabalhadores usava apenas um calção e um 
capacete com lanterna para desempenhar suas funções. Essas fotos de cotidiano, mesmo sendo registros posados, diferem das outras fotografias produzidas para a divulgação da exploração do mineral no sul do estado. Muitas imagens que circulam sobre o trabalho dos mineiros, buscam evidenciar o processo de mecanização da atividade intentando produzir efeitos de organização, segurança e tecnologia. Compondo ainda esse acervo fotográfico, o CEDOC também possui imagens do acidente ocorrido na Mina de Santana, que, apesar de não ter acontecido no município de Criciúma - cidade foco da atividade -, foram alvo de debates sobre seu potencial uso na oficina. As imagens registram o processo de retirada dos corpos dos 31 mineiros mortos no acidente decorrido em setembro de 1984.

O local do acidente ainda registra muitas marcas, sendo o cemitério da comunidade um lugar de memória da tragédia. No entanto, há anos parte da comunidade se mobiliza para construir um monumento em homenagem aos mortos, desejo que foi efetivado no dia 10 de setembro de 2020. A iniciativa demonstra os processos que a comunidade vem enfrentando para lidar com a memória traumática e, também, a falta de consenso entre os moradores sobre o projeto do memorial.

Figura 02 - Final de um dia de trabalho na mina (s. d.)

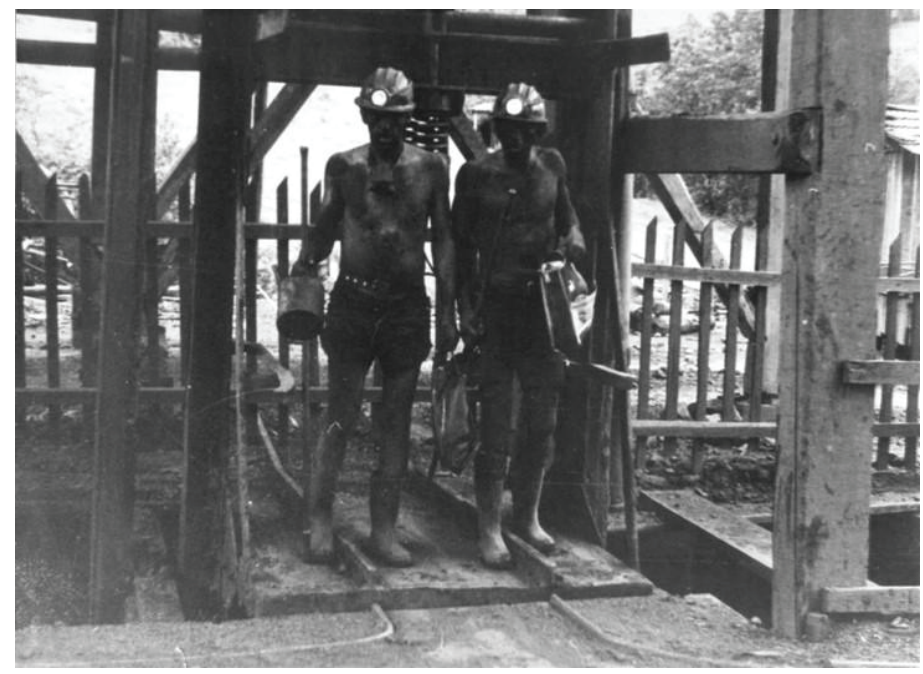

Fonte: Acervo CEDOC/UNESC 
Para a atividade educativa optamos por mencionar o acidente e mostrar algumas imagens que não expunham detalhes do ocorrido. Mesmo não acontecendo em Criciúma, a tragédia modificou todos os protocolos de trabalho na mineração, fato que possibilitou realizarmos algumas reflexões, principalmente relacionando o evento com as intensas greves realizadas pelos mineiros em busca de melhores condições de trabalho, salário e vida.

Escolhemos trabalhar ainda um audiovisual produzido pelo CEDOC e por acadêmicos/as do curso de História ${ }^{7}$ utilizando filmagens do Fundo Centro de Estudos, Documentação e Informação Popular (CEDIP) sobre a greve da Companhia Brasileira Carbonífera de Araranguá - CBCA, ocorrida em fins da década de 1980. Realizamos alguns recortes do material, pois as cenas gravadas durante as manifestações são bastante violentas. Mesmo assim, optamos por manter o audiovisual para proporcionar reflexões sobre a intensidade das manifestações na cidade, a organização sindical, as estratégias de negociação que envolviam acampamentos em lugares estratégicos da cidade, o uso de dinamites, confronto com as forças policiais e até mesmo a depredação da ferrovia.

A escolha dos documentos que seriam utilizados na atividade objetivava abordar a temática dando ênfase às vozes dissonantes que pouco ecoam pela cidade, ou que quando ecoam, sofrem diversas tentativas de silenciamento. Essas vozes expressam dores, tensionamentos, revoltas, traumas... são sensíveis para o emissor e também para o ouvinte. Esses temas sensíveis são fundamentais para a análise do passado histórico e por isso, devem estar presentes nas salas de aula, mesmo que exijam novas abordagens e metodologias. Essa necessária análise do processo ensino-aprendizagem viabiliza o diálogo com os espaços não formais de educação, como relatado nessa experiência.

Assim, nesse contexto, a oficina foi estruturada em duas etapas no intento de abordar as temáticas propostas e, ainda, sensibilizar a respeito da importância da preservação documental. A atividade desenvolvida ao longo de duas horas começava com a visita aos espaços físicos, apresentando brevemente alguns acervos. Após essa explanação, tinha início o diálogo com os/as participantes sobre o processo de instalação das atividades carboníferas em Criciúma. Durante a exposição foram projetadas várias imagens da cidade. As fotografias pertencentes à coleção Memória e Cultura do Carvão destacavam o processo de industrialização e urbanização de Criciúma durante o período de apogeu do setor. Por meio do diálogo com e sobre as imagens, buscamos 
enfatizar as modificações na paisagem urbana e, ainda, algumas características do trabalho nas minas de carvão, como a insegurança e a precariedade.

Os processos migratórios decorrentes das atividades carboníferas também foram abordados, evidenciando o aumento populacional em um curto período de tempo assim como os processos de urbanização que modificaram a estrutura da cidade a partir da ampliação das vilas operárias. Para essa análise, trabalhamos com imagens panorâmicas de Criciúma em diferentes temporalidades, incentivando a observação das mudanças na paisagem urbana. A preferência pela utilização das fotografias nesta atividade educativa busca evocar a perspectiva da imagem como discussão de temporalidades e condutora de memórias, com o intuito de discutir esta dupla habilitação da fotografia, incentivando os/as alunos/as a observar mudanças e permanências na paisagem urbana, tanto como vislumbre de uma sociedade passada ou como símbolo de um tempo perpetrado ao futuro.

Não são, pois, documentos os objetos da pesquisa, mas instrumentos dela: o objeto é sempre a sociedade. Por isto, não há como dispensar, aqui, também, a formulação de problemas históricos, para serem encaminhados e resolvidos por intermédio de fontes visuais, associadas a quaisquer outras fontes pertinentes. Assim, a expressão "História Visual" só teria algum sentido se se tratasse não de uma História produzida a partir de documentos visuais (exclusiva ou predominantemente), mas de qualquer tipo de documentos e objetivando examinar a dimensão visual da sociedade. "Visual" se refere, nestas condições, à sociedade e não às fontes para seu conhecimento - embora seja óbvio que aí se impõe a necessidade de incluir e, mesmo, eventualmente, privilegiar fontes de caráter visual. (MENEZES, 2002, p. 150-151)

Esse debate nos interessa ao ponto de utilizarmos as imagens para discussão de problemas históricos e sensíveis. Nesse caso, a sociedade carbonífera em Criciúma no século XX, perpetrado pelas memórias e documentos salvaguardados pelo CEDOC/UNESC. Como já mencionado, após essa análise mais global da cidade, a atividade buscou contemplar o trabalho realizado nas minas de carvão evidenciando o trabalho feminino e infantil, proporcionando reflexões sobre as jornadas de trabalho desenvolvidas pelas mulheres, como também sobre os aspectos da infância nas vilas operárias. Na sequência, a atividade buscava destacar os temas relacionados às condições de trabalho nas minas 
e os constantes acidentes. As doenças e mortes causadas pela atividade também eram debatidas, assim como as lutas para a melhoria nas condições de trabalho e vida. Ao utilizarmos as fotografias e o audiovisual, buscávamos questionar sobre os pontos de referência ali registrados e as mudanças/permanências ocorridas não somente no espaço urbano, como também na execução do trabalho do mineiro e dos seus meios de reivindicação.

Em seguida, iniciávamos a segunda etapa da oficina voltada a sensibilizar sobre a importância da preservação documental. Afinal, os documentos preservados pelo CEDOC nos ajudam a pensar outras narrativas sobre os processos carboníferos possibilitando novas pesquisas, abordagens e interpretações. Nesse sentido, a equipe do CEDOC enfatizava a necessidade do acondicionamento correto de livros e documentos, demonstrando brevemente algumas técnicas de conservação que auxiliam na prolongação da vida útil desses materiais. Para finalizar a atividade, desenvolvia-se uma ação prática de higienização documental com todas/os as/os participantes, momento em que a curiosidade pela técnica era aguçada proporcionando ricos debates sobre a preservação de documentos, ação que tem início com os documentos pessoais e familiares que sempre apareciam no debate.

Após essa etapa os/as alunos/as respondiam a um questionário de avaliação da atividade educativa. O breve questionário proporcionava perceber se os objetivos propostos foram alcançados e, também, sobre a necessidade de reavaliar a proposta de ação educativa, de modo que gerava novos dados para a discussão contínua do processo pela equipe do CEDOC e pelos/as professores/as participantes da atividade.

\section{CONSIDERAÇÕES FINAIS}

As oficinas desenvolvidas em regime de parceria entre o Centro de Memória e Documentação da UNESC - CEDOC e a Secretaria de Educação do Município de Criciúma durante o ano de 2016 resultaram em um processo de aproximação entre espaços formais e não formais de educação, demonstrando o potencial dessas ações. Por parte do CEDOC, essa parceria rendeu frutos posteriores. Além da prototipagem desta atividade educativa, ainda integrante do portfólio do CEDOC e realizada diversas vezes com outras escolas, os proponentes deslocaram essas atividades para outros espaços e cidades por 
meio do projeto de extensão Estruturas Carboníferas de Santa Catarina: Educação Patrimonial a partir do Acervo do CEDOC-UNESC, ocorrido entre os anos 2018 e 2020. De certa forma, as atividades também estimularam novos projetos de pesquisa e de inventário, como no caso do projeto já citado, Memórias e identidade: as estruturas carboníferas como patrimônio cultural de Santa Catarina, ocorrido entre 2016 e 2017, que publicou em formato de livro um inventário fotográfico mapeando diversas estruturas relacionadas às atividades carboníferas na região sul catarinense.

Entendemos que a oficina Indústria carbonifera em Criciúma: trabalho, cidade e operários/as, ao propor a discussão do trabalho do/a historiador/a com a utilização de acervos fotográficos e audiovisuais, propôs também o deslocamento da relação de ensino da sala de aula para um ambiente externo, os laboratórios do CEDOC/UNESC, sendo essa uma das propostas da educação não formal na qual "a categoria espaço é tão importante como a categoria tempo. O tempo da aprendizagem na educação não formal é flexível, respeitando as diferenças e as capacidades de cada um, de cada uma" (GADOTTI, 2005, p. 2). Não sem antes buscar ao máximo manter uma relação de diálogo e continuidade com as discussões realizadas nas aulas de História nas respectivas unidades escolares, justamente para referendar a opção realizada pelas professoras e professores de inserir a discussão da história regional em conteúdos já tradicionais da disciplina, de modo a ressaltar e problematizar as conexões já realizadas pelas/os alunas/os em suas rotinas cotidianas. As discussões envoltas propunham compreender as perspectivas de compreensão da História manifestadas pelo público da oficina e colocá-las em diálogo com as pesquisas e acervos salvaguardados no CEDOC, promovendo exercícios de consciência histórica (RUSEN, 2007). Muito para dar conta da necessidade de adaptação das atividades realizadas pelas professoras e professores no ambiente escolar, como os conteúdos letivos anuais, a proposta pedagógica das oficinas tomou por base as discussões de empatia histórica (LEE, 2003), sensibilizando as/os alunas/os e professores/as para pensar que as escolhas possíveis aos agentes históricos do passado não são refletidas diretamente pelas consequências de suas ações; em outras palavras, não sabiam dos desdobramentos futuros.

As conexões estabelecidas entre aspectos da revolução industrial e a exploração carbonífera ou, então, entre o trabalho feminino e infantil nesses dois 
momentos históricos visava muito mais do que estabelecer comparativos; possuía como objetivo ressaltar que as escolhas, ações e situações enfrentadas pelos agentes históricos eram balizadas pelas oportunidades de sua época, bem como não refletiam qualquer conhecimento das consequências de seus atos imediatos. É evidente que essas aproximações pedagógicas implicam em qualquer tipo de anacronismo, mas as observações serviram tanto para resguardar as temporalidades, como para estabelecer vínculos entre o passado imediato de uma Criciúma preenchida pela exploração carbonífera e processos decorridos há séculos.

As fotografias e audiovisuais escolhidos como recursos didáticos, além de destacar visualmente os exercícios de estudo da História, também tiveram a função de trazer à tona as memórias dissonantes desse período tão vivo na cidade e na memória de seus/suas habitantes. Os temas sensíveis discutidos nestas oficinas foram propostos para estabelecer diálogos menos marcados pelos ressentimentos com a exploração carbonífera, sem menosprezar as contribuições ao desenvolvimento regional e sem referendar discursos laudatórios. A proposta de apresentar os discursos dissonantes é também uma maneira de promover diálogos democráticos e inclusivos para os personagens do tempo presente, preenchidos pelos discursos e intenções de um passado que insiste em permanecer vivo nas memórias da cidade, mesmo ante os processos de substituição das narrativas e modernidades identitárias.

\section{REFERÊNCIAS}

ALVES, Ismael Gonçalves. (Re)construindo a maternidade: as políticas públicas materno-infantis brasileiras e suas implicações na Região Carbonífera Catarinense (1920-1960). Tese (Doutorado em História). Setor de Ciências Humanas, Universidade Federal do Paraná. Curitiba, 2014. 294 f.

ALVES, Ismael Gonçalves. Faces da assistência social do setor carbonifero catarinense (Criciúma, 1930-1960). Dissertação (Mestrado em História). Centro de Ciências Humanas e da Educação, Universidade do Estado de Santa Catarina. Florianópolis, 2009. $161 \mathrm{f}$.

BEZERRA, Marcia. Patrimônios e educação patrimonial. In.: CARVALHO, Aline; MENGUELLO, Cristina (Orgs.). Dicionário temático de patrimônio: debates contemporâneos. Campinas: Editora da Unicamp, 2020, p. 245-248. 
CAROLA, Carlos Renato. Dos subterrâneos da História: as trabalhadoras das minas de carvão de Santa Catarina (1937-1964). 1. ed. Florianópolis: UFSC, 2002.

CAROLA, Carlos Renato. Memória e cultura do carvão em Santa Catarina: impactos sociais e ambientais. Santa Cruz do Sul: EDUNISC, 2011.

CAROLA, Carlos Renato; DASSI, Nilson. Era uma vez o rio Mãe Luzia.... Criciúma: Editora UNESC, 2014.

COSTA, Marli de Oliveira. Artes de viver: recriando e reinventando espaços - memórias das famílias da vila operária mineira Próspera Criciúma (1945/1961). Dissertação (Mestrado em História). Centro de Filosofia e Ciências Humanas, Universidade Federal de Santa Catarina. Florianópolis, 1999. 206 f.

COSTA, Marli de Oliveira. Infâncias e "artes" das crianças: memórias, discursos e fazeres (sul de Santa Catarina - 1920 a 1950). Tese (Doutorado em Educação). Faculdade de Educação, Universidade Federal do Rio Grande do Sul. Porto Alegre, 2009. $293 \mathrm{f}$.

COSTA, Marli de Oliveira; OSÓRIO, Paulo Sérgio. Memórias e Identidades: as estruturas carboníferas como patrimônio cultural de Santa Catarina. Tubarão/Criciúma: Copiart/EdiUNESC, 2017.

GADOTTI, Moacir. A questão da educação formal/não-formal. In: Droit à l'éducation: solution à tous les problémes ou probléme sans solution?. Sion: Institut internacional des droit de l'Enfant c/o Institut Universitaire Kurt Bösch, 2005.

GOHN, Maria da Gloria. Educação não-formal, educador(a) social e projetos sociais de inclusão social. Meta: avaliação, Rio de Janeiro, v. 1, n. 1, p. 28-43, 2009.

GOULARTI FILHO, Alcides. Formação econômica de Santa Catarina. Florianópolis: Cidade Futura, 2002.

GOULARTI FILHO, Alcides. Memória e cultura do carvão em Santa Catarina. Florianópolis: Cidade Futura, 2004.

LEE, Peter. Nós fabricamos carros e eles tinham que andar a pé: compreensão das pessoas do passado. In.: BARCA, Isabel. Educação Histórica e Museus. Minho/PT: Universidade do Minho, 2003.

MAUAD, Ana Maria; LOPES, Marcos Felipe de Brum. História e Fotografia. In: CARDOSO, Ciro Flamarion; VAINFAS, Ronaldo. Novos domínios da história. Rio de Janeiro: Elsevier, 2012.

MENEGUELLO, Cristina. Patrimônios difíceis (sombrios). In.: CARVALHO, Aline; MENGUELLO, Cristina (Orgs.). Dicionário temático de patrimônio: debates contemporâneos. Campinas: Editora da Unicamp, 2020. p. 245-248.

MENEGUELLO, Cristina; BORGES, Viviane. T. Patrimônio, memória e reparação: a preservação dos lugares destinados à hanseníase no estado de São Paulo. Patrimônio e Memória, UNESP, v. 14, p. 345-374, 2018. 
MENEZES, Carlyle T. B.; CAROLA, Carlos Renato. A politica da modernização, a legislação ignorada e a degradação socioambiental da indústria carbonífera (19301970). In: CAROLA, Carlos Renato (Org.). Memória e Cultura do Carvão em Santa Catarina: impactos sociais e ambientais. $1^{\mathrm{a} e d}$. Santa Cruz do Sul: EDUNISC, 2010, p. 196-218.

MENEZES, Ulpiano Toledo Bezerra de. A fotografia como documento - Robert Capa e o miliciano abatido na Espanha: sugestões para um estudo histórico. Tempo, Rio de Janeiro, n. 14, p. 131-151, 2002.

MIRANDA, Antonio Luiz. Trajetórias e experiências do movimento operário sindical de Criciúma-SC: da ditadura militar à Nova República - 1963/1990. Tese (Doutorado em História). Centro de Filosofia e Ciências Humanas, Universidade Federal de Santa Catarina. Florianópolis, 2013. 238 f.

MONTEIRO, Renato de Araújo. As legislações de proteção ao patrimônio histórico e os tombamentos municipais em Criciúma/SC. In.: I Simpósio de Patrimônio Cultural de Santa Catarina - "Patrimônio Cultural: Saberes e Fazeres Partilhados", Florianópolis, 21 e 22 de novembro de 2013.

RABELO, Giani. Entre o hábito e o carvão: pedagogias missionárias no sul de Santa Catarina na segunda metade do século XX. Tese (Doutorado em Educação). Faculdade de Educação, Universidade Federal do Rio Grande do Sul. Porto Alegre, 2008. $415 \mathrm{f}$.

RÜSEN, Jörn. História viva. Teoria da história III: formas e funções do conhecimento histórico. Brasília: Ed. UNB, 2007.

STEPHANOU, Maria. Evidências da História, memórias entretecidas: experiências e novas aproximações em torno do patrimônio. In: GIL, Carmem Zeli de Vargas; TRINDADE, Rhuan Targino Zaçleski (Orgs.). Patrimônio cultural e ensino de História. Porto Alegre: Edelbra, 2014.

TEIXEIRA, José Paulo. Os donos da cidade. Florianópolis: Insular, 1996.

VOLPATO, Terezinha Gascho. A pirita humana. Os mineiros de Criciúma. Florianópolis: Editora da UFSC, 1984.

VOLPATO, Terezinha Gascho. Vidas Marcadas. Tubarão: Unisul, 2001.

\section{NOTAS}

${ }^{1}$ Proposta identitária elaborada no período de comemoração do centenário da cidade que procura enfatizar grupos de imigrantes que colonizaram o município.

${ }^{2}$ A ponte de ferro do bairro São Roque era parte da antiga passarela utilizada no centro da cidade para passagem sobre a linha férrea que dividia a região central. Com a transposição dos trilhos e a construção de uma avenida de ligação de norte a sul da cidade, a antiga pas- 
sarela foi também transplantada para funcionar como uma ponte sobre o rio Sangão no bairro São Roque, fronteira com o município de Forquilhinha.

${ }^{3}$ A Mina Modelo Caetano Sônego foi a primeira mina de exploração de carvão da cidade. Localizada no bairro Mina Brasil, possui características distintas por ser uma mina de encosta, com perfuração horizontal e não vertical como é recorrente na região. Esta mina foi transformada em espaço de visitação em 1984 e fechada como museu em 2006.

${ }^{4} \mathrm{O}$ Monumento aos Homens do Carvão, popularmente conhecido como Monumento ao Mineiro é muito famoso na cidade, também devido à sua localização na Praça Nereu Ramos, principal praça da cidade, também funcionando como espaço de lazer e comércio. É importante ressaltar que mesmo conhecido como "mineiro do centro" o monumento foi realizado como homenagem aos mineradores, empresários das indústrias carboníferas. Outra curiosidade, e que modifica a perspectiva de abordagem sobre este monumento, é o fato dele ser basicamente a estátua de um mineiro com as fotografias dos mineradores.

${ }^{5} \mathrm{O}$ tombamento do antigo prédio do Departamento Nacional de Produção Mineral, hoje Centro Cultural Jorge Zanatta, se deu muito mais pelo reconhecimento desta edificação como espaço de cultura no centro da cidade. A construção fica no eixo central de ligação leste-oeste, localizada em uma das ruas principais da cidade, Rua Coronel Pedro Benedet, nas imediações da Praça Nereu Ramos. Como sede do Departamento Nacional de Produção Mineral, o espaço funcionava mais como suporte burocrático para autorizações e fiscalização da exploração carbonífera e também como espaço de assistência de saúde em alguns casos. O espaço também foi utilizado como prisão nos primeiros anos de Ditadura Militar, até a chegada do $28^{\circ}$ G.A.C. do Exército brasileiro.

${ }^{6}$ A tragédia ocorreu na madrugada do dia 10 de setembro de 1984, quando uma explosão causada por gás metano levou a óbito os 31 mineiros que estavam a 80 metros no subsolo, grande parte deles por intoxicação. Por causa do desmoronamento e também pela grande quantidade de gás presente no local, a retirada dos corpos só foi possível três dias depois do acidente.

${ }^{7}$ Audiovisual produzido para a disciplina de "Oficina de Ensino e Pesquisa: História, Imagem e Som" no ano de 2013.

Artigo submetido em 30 de outubro de 2020. Aprovado em 28 de janeiro de 2021. 